\title{
Obesity and the COVID-19: Analysis of the clinical and epidemiological profiles of 138 individuals
}

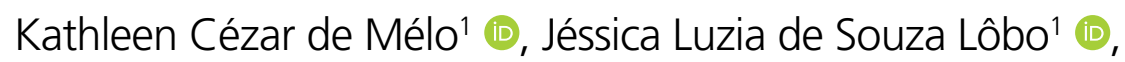 \\ Adeilton Gonçalves da Silva Junior ${ }^{2}$ (D), Rodrigo Feliciano do Carmo ${ }^{3,4}$ (), \\ Carlos Dornels Freire de Souza ${ }^{4,5 *}$
}

\section{SUMMARY}

INTRODUCTION: Coronavirus disease 2019 (COVID-19) is the disease caused by a novel coronavirus, severe acute respiratory syndrome coronavirus 2 (SARS-CoV-2). In the ongoing obesity pandemic, its coexistence with COVID-19 becomes worrying and has a less favorable outcome.

OBJECTIVE: This study aimed to describe the clinical and epidemiological profiles of confirmed cases of COVID-19 in individuals with obesity in the state of Alagoas.

METHODS: The observational cross-sectional study involving 138 confirmed cases of COVID-19 who had obesity as a comorbidity reported at the time of notification of the disease. The data were collected from the COVID-19 database in the state of Alagoas, and the variables analyzed were sex, age (and age group), race/color, outcome, clinical manifestations, and associated comorbidities. The Kolmogorov-Smirnov, Mann-Whitney $U, \chi^{2}$, or Fisher's exact tests were performed as appropriate. The significance was set at 5 and $95 \%$ confidence intervals. RESULTS: There was a predominance of females ( $55.1 \% ; n=76)$, aged $<60$ years $(70.3 \% ; n=97)$ and brown race/color $(n=76 ; 55.1 \%)$. The most prevalent symptoms were cough ( $n=84 ; 60.9 \%)$, fever $(n=78 ; 56.5 \%)$, headache $(n=36 ; 26.1 \%)$, and adynamia $(n=28 ; 20.3 \%)$. The median age was 49 years, with no difference between genders $(p=0.340)$. The lethality rate was $17.4 \%(n=24)$, being higher in the male population ( $22.6 \%$ in males and $13.2 \%$ in females). Of the 24 deaths, $13(54.2 \%)$ were recorded in the elderly people. In addition to obesity, $54.3 \%(n=75)$ had systemic arterial hypertension and $30.4 \%(n=42)$ had diabetes mellitus. There was no difference in the prevalence of comorbidity between genders.

CONCLUSIONS: The profile studied demonstrates that obesity represents a challenge for coping with COVID-19.

KEYWORDS: Obesity. Epidemiology. Coronavirus Infections.

\section{INTRODUCTION}

Coronavirus disease 2019 (COVID-19), a disease caused by the novel coronavirus, severe acute respiratory syndrome coronavirus 2 (SARS-CoV-2), was first recorded in December 2019 in the city of Wuhan, China ${ }^{1}$. On March
11, 2020, the World Health Organization (WHO) declared pandemic status ${ }^{2}$.

On August 17, 2020, the countries had already registered $21,809,170$ cases and 772,479 deaths due to COVID-19 globally. Among the 188 countries analyzed, the United States,

\footnotetext{
'Universidade Federal de Alagoas, Departamento de Medicina - Alagoas (AL), Brazil.

${ }^{2}$ Núcleo de Epidemiologia - Juazeiro (BA), Brazil.

${ }^{3}$ Universidade Federal do Vale do São Franscisco, Postgraduate Program in Health and Biological Sciences - Petrolina (PB), Brazil.

${ }^{4}$ Universidade Federal do Vale do São Franscisco, Postgraduate Program in Biosciences - Petrolina (PB), Brazil.

${ }^{5}$ Universidade Federal de Alagoas, Programa de Pós-graduação em Saúde da Família, Departamento de Medicina. Arapiraca (AL), Brazil.

*Corresponding author: carlos.freire@arapiraca.ufal.br

Conflicts of interest: the authors declare there are no conflicts of interest. Funding: none.

Received on August 26, 2020. Accepted on September 20, 2020.
} 
Brazil, and India are ranked top three countries with 5.4, 3.3, and 2.6 million confirmed cases, respectively ${ }^{3}$.

Obesity has been associated with a worse prognosis of viral infections, as in Asian influenza in 1957-1960, H1N1 in 2009, and currently, COVID-194. The unfavorable effects can be attributed to the metabolic and immunological breakdown, due to the chronic inflammation that accompanies obesity and the metabolic syndrome, with abnormal production of cytokines and increased acute phase reagents. Other factors, such as insulin resistance, dyslipidemia, atherosclerosis, type 2 diabetes, hypertension, and asthma, are comorbidities that adversely affect COVID-19 patients ${ }^{5,6}$.

The coexistence of an ongoing obesity pandemic, which in some Western countries reached up to $40 \%$ of the adult population, e.g., the United States ${ }^{7,6}$, COVID-19 can become even more dangerous. In Brazil, the number of obese people has increased to $72.03 \%$ between 2006 and 2019, according to Surveillance of Risk and Protection Factors for Chronic Diseases by Telephone Survey (Vigitel) ${ }^{8}$. About $55.4 \%$ of the population is overweight and $20.3 \%$ of them are obese adults, being similar between men and women ${ }^{8}$. Given the above and the need for knowledge production, this study aimed to describe the clinical and epidemiological profiles of confirmed cases of COVID-19 in individuals with obesity reported in Alagoas, Brazil.

\section{METHODS}

This is a cross-sectional observational study involving 138 confirmed cases of COVID-19 who had obesity as a comorbidity reported at the time of notification of the disease.

The data were collected from the COVID-19 database in the state of Alagoas available at http://www.dados.al.gov.br/dataset/painel-covid19-alagoas on August 1, 2020. The following variables were analyzed: gender, age (and age group), race/color, outcome, clinical manifestations, and associated comorbidities.

For statistical analysis, the normality of the data was assessed by the Kolmogorov-Smirnov test. Continuous variables were presented by means of measures of central tendency and dispersion, and categorical variables were presented by means of absolute and relative frequencies. The Mann-Whitney $U$ test was used for continuous variables and the chi-square or Fisher's exact test was used for categorical variables, as appropriate. The significance was set at $5 \%$ and $95 \%$ confidence intervals. The analyses were performed using SPSS software (IBM SPSS Statistics for Windows, Version 22.0.IBM Corp., Armonk, NY).

Since these are secondary open access data, in which it is not possible to identify individuals, this study did not require the appreciation of the Research Ethics Committee.

\section{RESULTS}

Of the 138 records analyzed, $55.1 \%(\mathrm{n}=76)$ were females, with a minimum age of 15 and a maximum age of 84 years. The median age was 49 years (interquartile range [IQR] 21), with no difference between genders $(\mathrm{p}=0.340)$. The lethality rate was $17.4 \%(n=24)$, being higher in the male population $(22.6 \%$ in males and $13.2 \%$ in females). When comparing deaths and survivors, a significant difference in age was observed $(p=0.004)$ : the median age of death was 61.5 (IQR 25) and of survivors was 47 (IQR 21). Additionally, the number of deaths increased with aging $(\mathrm{p}=0.007)$. Of the 24 deaths, 13 (54.2\%) were recorded in the elderly people (Figure 1 and Table 1).

In studying the epidemiological profile, there was a predominance of the population aged $<60$ years $(70.3 \%$; $n=97)$ and brown race $(\mathrm{n}=76 ; 55.1 \%)$. The most prevalent symptoms were cough $(\mathrm{n}=84 ; 60.9 \%)$, fever $(\mathrm{n}=78 ; 56.5 \%)$, headache $(n=36 ; 26.1 \%)$, and adynamia $(n=28 ; 20.3 \%)$. Only the variables cough and fever showed differences between the sexes $(\mathrm{p}=0.047$ and $\mathrm{p}=0.004)$. In addition to obesity, $54.3 \%(\mathrm{n}=75)$ had systemic arterial hypertension and $30.4 \%(n=42)$ had diabetes mellitus. There was no difference in the prevalence of comorbidity between genders (Table 1).

\section{DISCUSSION}

The WHO classifies both COVID-19 and obesity as international public health emergencies. The association between the two conditions is not yet fully known, but obesity is known to promote a secretion of proinflammatory cytokines, and obese individuals have an impaired immune response. The angiotensin II-converting enzyme (ACE II) is expressed in quantity in adipose tissue and has a high affinity for SARS-CoV-2, which may explain the less favorable outcomes of COVID-19 in obese patients ${ }^{9-11}$.

Global clinical observations indicate that the virus can cause more serious complications in obese individuals or those with related conditions. In a Chinese study with 30 infected patients, those with high body mass index (BMI) (>27), therefore were considered obese, had the disease with more severe symptoms compared with patients with a BMI of $22^{12}$.

In a retrospective cohort of 124 patients from France, obesity (BMI $>30 \mathrm{~kg} / \mathrm{m}^{2}$ ) was present in $47.6 \%$ of the intensive care unit (ICU) patients, which is associated with the need for invasive mechanical ventilation (IMV) ${ }^{13}$. In a study with 3,615 patients from New York, it is demonstrated that patients with a BMI of 30-34.9 were 2.0 and 1.8 times more likely to be admitted to acute and critical care, respectively, than individuals with a $\mathrm{BMI}$ of $<30^{14}$. Additionally, reviews carried out 


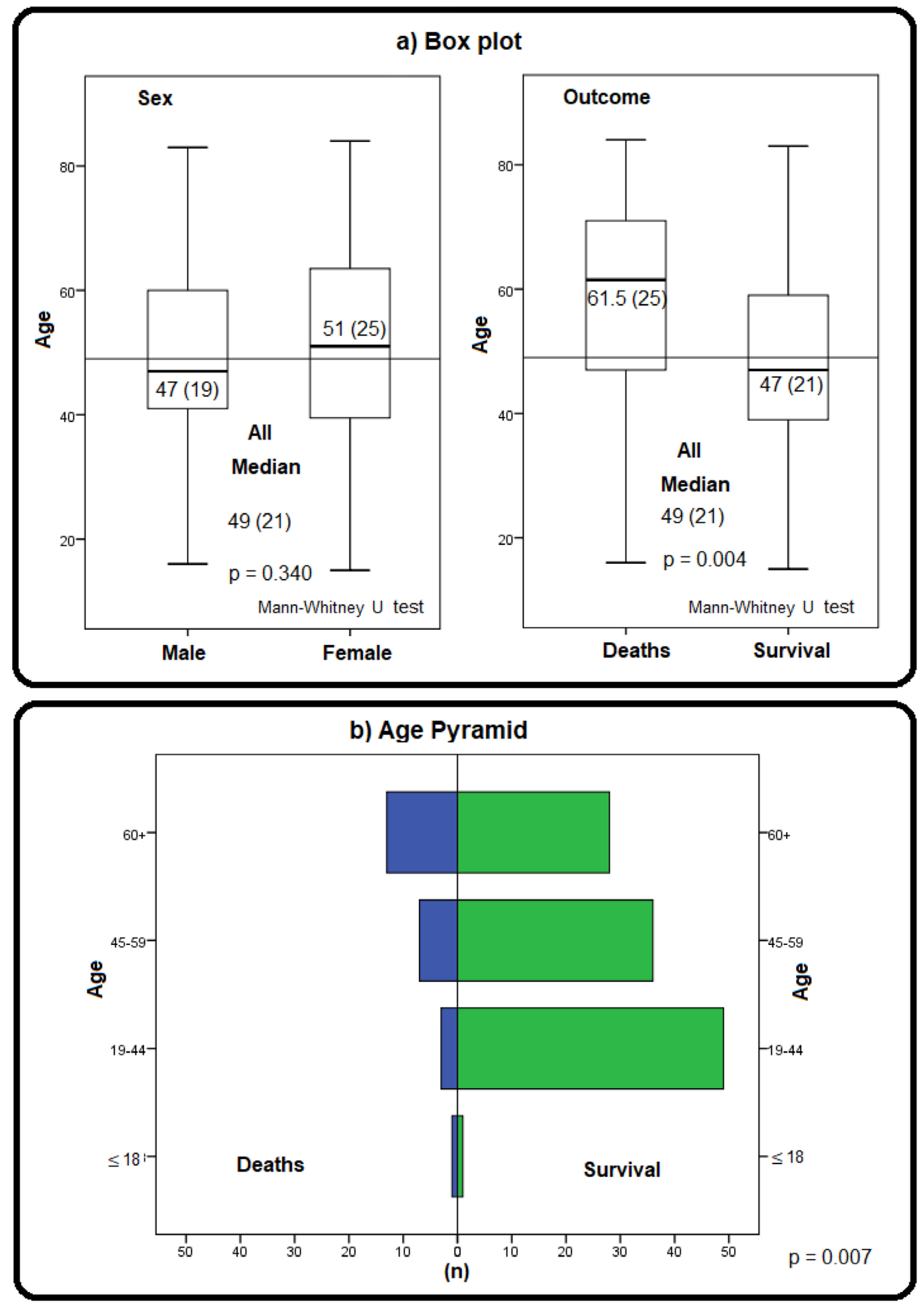

Figure 1. Age distribution of COVID-19 cases in individuals with reported obesity. Alagoas, Brazil $(n=138)$. 
Table 1. Clinical and epidemiological characterization of confirmed cases of COVID-19 in individuals with reported obesity. Alagoas, Brazil $(n=138)$.

\begin{tabular}{|c|c|c|c|c|c|c|c|}
\hline & \multicolumn{2}{|c|}{$\begin{array}{c}\text { Male } \\
(n=62 ; 44.9 \%)\end{array}$} & \multicolumn{2}{|c|}{$\begin{array}{c}\text { Female } \\
(\mathrm{n}=76 ; 55.1 \%)\end{array}$} & \multicolumn{2}{|c|}{$\begin{array}{c}\text { Total } \\
(\mathrm{n}=138 ; 100 \%) \\
\end{array}$} & \multirow{2}{*}{ p-value* } \\
\hline & $\mathrm{n}$ & $\%$ & $\mathrm{n}$ & $\%$ & $\mathrm{n}$ & $\%$ & \\
\hline \multicolumn{8}{|l|}{ Age } \\
\hline$\geq 60$ & 18 & 29.0 & 23 & 30.3 & 41 & 29.7 & \multirow{2}{*}{0.513} \\
\hline$<60$ & 44 & 71.0 & 53 & 69.7 & 97 & 70.3 & \\
\hline \multicolumn{8}{|l|}{ Race/color } \\
\hline East Asian & 1 & 1.6 & 1 & 1.3 & 2 & 1.4 & \multirow{5}{*}{0.141} \\
\hline White & 11 & 17.7 & 11 & 14.5 & 22 & 15.9 & \\
\hline Unknown & 21 & 33.9 & 13 & 17.1 & 34 & 24.6 & \\
\hline Pardo & 27 & 43.5 & 49 & 64.5 & 76 & 55.1 & \\
\hline Black & 2 & 3.2 & 2 & 2.6 & 4 & 2.9 & \\
\hline \multicolumn{8}{|l|}{ Outcome } \\
\hline Death & 14 & 22.6 & 10 & 13.2 & 24 & 17.4 & \multirow{2}{*}{0.110} \\
\hline Survival & 48 & 77.4 & 66 & 86.8 & 114 & 82.6 & \\
\hline \multicolumn{8}{|l|}{ Clinical manifestations } \\
\hline Fever & 37 & 59.7 & 41 & 53.9 & 78 & 56.5 & 0.308 \\
\hline Cough & 43 & 69.4 & 41 & 53.9 & 84 & 60.9 & 0.047 \\
\hline Headache & 9 & 14.5 & 27 & 35.5 & 36 & 26.1 & 0.004 \\
\hline Loss of strength & 9 & 14.5 & 19 & 25.0 & 28 & 20.3 & 0.094 \\
\hline Difficulty breathing & 6 & 9.7 & 8 & 10.5 & 14 & 10.1 & 0.55 \\
\hline Dyspnea & 11 & 17.7 & 6 & 7.9 & 17 & 12.3 & 0.068 \\
\hline Myalgia & 4 & 6.5 & 12 & 15.8 & 16 & 11.6 & 0.073 \\
\hline Odynophagia & 6 & 9.7 & 7 & 9.2 & 13 & 9.4 & 0.575 \\
\hline \multicolumn{8}{|l|}{ Comorbidities } \\
\hline Cardiovascular disease & 8 & 12.9 & 5 & 6.6 & 13 & 9.4 & 0.166 \\
\hline Diabetes mellitus & 18 & 29.0 & 24 & 31.6 & 42 & 30.4 & 0.446 \\
\hline Chronic respiratory disease & 3 & 4.8 & 2 & 2.6 & 5 & 3.6 & 0.404 \\
\hline Systemic arterial hypertension & 31 & 50.0 & 44 & 57.9 & 75 & 54.3 & 0.225 \\
\hline Chronic renal disease & 3 & 4.8 & 1 & 1.3 & 4 & 2.9 & 0.237 \\
\hline
\end{tabular}

*Exact test Fisher.

also ratify the relationship between obesity and worse prognosis for COVID-195,15.

A retrospective study of 3,406 patients at a university hospital in the United States showed that morbid obesity is strongly associated with the mortality of individuals hospitalized over 50 years. Of the hospitalized individuals, the lethality in individuals above 50 years old reached $38 \%$, while in the young population it was $10.5 \%{ }^{9}$. In our investigation, the median age of individuals who died was substantially higher than the age observed in survivors ( 61.5 and 47 , respectively). In addition, the age pyramid shows the concentration of deaths in the elderly population.

Several studies have already reported the advanced age as a risk factor for COVID-19 mortality, in addition to being associated with longer hospital stay and high viral load. The factors, such as immunosenescence (i.e., reduced efficiency of 
natural immune cells in the elderly), chronic subclinical systemic inflammation of old age, and accumulation of comorbidities, are related to the worst prognosis of the disease in this group $^{16}$. The retrospective cohort study with 200 patients in New York identified 46 obese (BMI $\left.\geq 35 \mathrm{~kg} / \mathrm{m}^{2}\right)$, among which $20.4 \%$ were 65 years old or more ${ }^{17}$. The study also observed that, among the elderly, both malnutrition and obesity were linked to an unfavorable outcome for patients ${ }^{17}$. In Brazil, about $20.9 \%$ of the elderly population is obese $\left(\mathrm{BMI} \geq 30 \mathrm{~kg} / \mathrm{m}^{2}\right)^{8}$.

In addition to age and obesity, other comorbidities and underlying risk factors can act together, increasing the risk of complications and mortality due to COVID-19. Diabetes mellitus, arterial hypertension, cardiovascular disease, chronic kidney disease, chronic lung disease, cancer, immunosuppression, and smoking are among the most common risk factors ${ }^{18}$. In an investigation carried out in Pernambuco, the presence of cardiovascular diseases accelerated mortality from COVID-19 in 4 days $^{19}$. In our study, $54.3 \%$ of individuals with obesity had systemic arterial hypertension and $30.4 \%$ had diabetes mellitus.

The prevalence of multiple comorbidities in individuals hospitalized with COVID-19 has been widely reported. In a study with 103 patients hospitalized with COVID-19 in the state of Rhode Island (the United States), the most common comorbidity was arterial hypertension, followed by diabetes mellitus and heart disease $(64.0,36.8$, and $24.2 \%$, respectively) ${ }^{2}$. A study carried out in Pernambuco, involving 197 deaths due to COVID-19 who had underlying cardiovascular diseases, $78.7 \%$ of them had two or more comorbidities, the most common being diabetes mellitus and obesity ${ }^{20}$. The overlap of multiple risk factors should be the subject of scientific investigations to estimate the importance of each one in COVID-19 severity and mortality.

Even considering the methodological care adopted, this study has following limitations. Secondary data are subject to the influence of collection procedures, such as filling in the notification form and typing, which may result in inconsistent records. Obesity reported in this study had no precise specification of the classification method, such as BMI or weight and height. The inclusion of weight and height variables in the notification forms could have reduced this bias and allowed a more accurate analysis of the relationship between obesity and COVID-19 in Brazil.

\section{CONCLUSION}

Based on the observed profile, this study showed that obesity represents an additional challenge in coping with the COVID-19 pandemic, mainly due to the high lethality and the overlapping of comorbidities in the same individual. We emphasize the importance of protecting the obese population from contamination by SARS-CoV-2 and of establishing measures that make the diagnosis possible and ensure adequate clinical monitoring for those who are infected by the virus. In addition, the need to strengthen public policies that have an effect on risk factors becomes an urgency.

\section{AUTHORS" CONTRIBUTIONS}

KCM: Conceptualization, Data Curation, Formal Analysis, Methodology, Writing - Original Draft, Writing - Review \& Editing. JLSL: Conceptualization, Data Curation, Formal Analysis, Methodology, Writing - Original Draft, Writing Review \& Editing. AGSJ: Conceptualization, Data Curation, Formal Analysis, Methodology, Writing - Original Draft, Writing - Review \& Editing. RFC: Conceptualization, Data Curation, Formal Analysis, Methodology, Writing - Original Draft, Writing - Review \& Editing. CDFS: Conceptualization, Data Curation, Formal Analysis, Methodology, Writing Original Draft, Writing - Review \& Editing.

\section{REFERENCES}

1. Petrilli CM, Jones SA, Yang J, Rajagopalan $H$, O'Donnell $L$, Chernyak $Y$, et al. Factors associated with hospital admission and critical illness among 5279 people with coronavirus disease 2019 in New York City: prospective cohort study. BMJ. 2020;369:m1966. https://doi.org/10.1136/bmj.m1966

2. World Health Organization Coronavirus disease 2019 (COVID-19): Situation Report - 51. Geneva: World Health Organization; 2020. [cited on Apr 26, 2020]. Available from: https://www.who.int/docs/default-source/ coronaviruse/situation-reports/20200311-sitrep-51-covid-19. pdf?sfvrsn=1 ba62e57_10
3. Center for Systems Science and Engineering (CSSE) at Johns Hopkins University. COVID-19 Dashboard by the Center for Systems Science and Engineering (CSSE) at Johns Hopkins University. Baltimore: Johns Hopkins University; 2020. [cited on Aug 17, 2020]. Available from: https:// www.arcgis.com/apps/opsdashboard/index.html\#/ bda7594740fd40299423467b48e9ecf6

4. Michalakis K, Ilias I. SARS-CoV-2 infection and obesity: common inflammatory and metabolic aspects. Diabetes Metab Syndr. 2020;14(4):469-71. https://doi.org/10.1016/j. dsx.2020.04.033 
5. Földi M, Farkas N, Kiss S, Zádori N, Váncsa S, Szakó L, et al; KETLAK Study Group. Obesity is a risk factor for developing critical condition in COVID-19 patients: a systematic review and meta-analysis. Obes Rev. 2020;21(10):e13095. https:// doi.org/10.1111/obr.13095

6. Chiappetta S, Sharma AM, Bottino V, Stier C. COVID-19 and the role of chronic inflammation in patients with obesity. Int J Obes (Lond). 2020;44(8):1790-2. https://doi.org/10.1038/ s41366-020-0597-4

7. Trust for America's Health (TFAH). The state of obesity: better policies for a healthier America 2018. Washington: Trust for America's Health; 2020. [cited on Aug 16, 2020]. Available from: https://www.tfah.org/wp-content/uploads/2018/09/ TFAH-2018-ObesityReport-FINAL.pdf

8. Brazil. Ministério da Saúde. Secretaria de Vigilância em Saúde. Departamento de Análise em Saúde e Vigilância de Doenças Não Transmissíveis. Vigitel Brazil 2019: vigilância de fatores de risco e proteção para doenças crônicas por inquérito telefônico: estimativas sobre frequência e distribuição sociodemográfica de fatores de risco e proteção para doenças crônicas nas capitais dos 26 estados Brazileiros e no Distrito Federal em 2019 [recurso eletrônico]. Brasília: Ministério da Saúde, Secretaria de Vigilância em Saúde, Departamento de Análise em Saúde e Vigilância de Doenças não Transmissíveis. Brasília: Ministério da Saúde; 2020. [cited on Aug 17, 2020]. Available from: https://portalarquivos. saude.gov.br/images/pdf/2020/April/27/vigitel-Brazil-2019vigilancia-fatores-risco.pdf

9. Klang E, Kassim G, Soffer S, Freeman R, Levin MA, Reich DL. Severe obesity as an independent risk factor for COVID-19 mortality in hospitalized patients younger than 50 . Obesity (Silver Spring). 2020;28(9):1595-9. https://doi.org/10.1002/ oby. 22913

10. Petrakis D, Margină D, Tsarouhas K, Tekos F, Stan M, Nikitovic D, et al. Obesity - a risk factor for increased COVID-19 prevalence, severity and lethality (Review). Mol Med Rep. 2020;22(1):9-19. https://doi.org/10.3892/mmr.2020.11127

11. Yang J, Hu J, Zhu C. Obesity aggravates COVID-19: a systematic review and meta-analysis. J Med Virol. 2021 Jan;93(1):257-61. https://doi.org/10.1002/jmv.26237

12. Liu M, He P, Liu HG, Wang XJ, Li FJ, Chen S, et al. Clinical characteristics of 30 medical workers infected with new coronavirus pneumonia. [Clinical characteristics of 30 medical workers infected with new coronavirus pneumonia]. Zhonghua Jie He He Hu Xi Za Zhi. 2020;43(3):209-14. https://doi. org/10.3760/cma.j.issn

13. Simonnet A, Chetboun M, Poissy J, Raverdy V, Noulette J, Duhamel $A$, et al. High prevalence of obesity in severe acute respiratory syndrome coronavirus-2 (SARS-CoV-2) requiring invasive mechanical ventilation. Obesity (Silver Spring). 2020;28(7):1195-9. https://doi.org/10.1002/oby.22831

14. Lighter J, Phillips M, Hochman S, Sterling S, Johnson D, Francois $\mathrm{F}$, et al. Obesity in patients younger than 60 years is a risk factor for Covid-19 hospital admission. Clin Infect Dis. 2020;71(15):896-7. https://doi.org/10.1093/cid/ciaa415

15. Korakas E, Ikonomidis I, Kousathana F, Balampanis K, Kountouri A, Raptis A, et al. Obesity and COVID-19: immune and metabolic derangement as a possible link to adverse clinical outcomes. Am J Physiol Endocrinol Metab. 2020;319(1):E105-9. https:// doi.org/10.1152/ajpendo.00198.2020

16. Kang SJ, Jung SI. Age-related morbidity and mortality among patients with COVID-19. Infect Chemother. 2020;52(2):15464. https://doi.org/10.3947/ic.2020.52.2.154

17. Palaiodimos L, Kokkinidis DG, Li W, Karamanis D, Ognibene J, Arora S, et al. Severe obesity, increasing age and male sex are independently associated with worse in-hospital outcomes, and higher in-hospital mortality, in a cohort of patients with COVID-19 in the Bronx, New York. Metabolism. 2020;108:154262. https:// doi.org/10.1016/j.metabol.2020.154262

18. Wexler DJ. Coronavirus disease 2019 (COVID-19): issues related to diabetes mellitus in adults. Alphen aan den Rijn: UpToDate; 2020. [cited on Aug 17, 2020]. Available from: https://www.uptodate. com/contents/coronavirus-disease-2019-covid-19-issuesrelated-to-diabetes-mellitus-in-adults/print?search=covid \%20 diabetes\&source=search_result\&selectedTitle=1 150\&usage_ type $=$ default\&display_rank $=1$

19. Souza CDF, Leal TC, Santos LG. Does existence of prior circulatory system diseases accelerate mortality due to COVID-19? Arq Bras Cardiol. 2020;115(1):146-7. https://doi.org/10.36660/ abc. 20200486

20. Souza CDF, Leal TC, Santos LG. Circulatory system diseases in patients with COVID-19: description of clinical and epidemiological profile of 197 deaths. Arq Bras Cardiol. 2020;115(2):281-3. https://doi.org/10.36660/abc.20200453 